\title{
Hongo del orden mucorales identificado en los ambientes del área Covid - 19 de un hospital de alta complejidad
}

\section{Mucoral order fungus identified in the environments from Covid-19 area of a high complexity hospital}

El orden Mucorales está compuesto por los géneros Mucor, Rhizopus y Rhizomucor, estos hongos son de importancia médica y causan mucormicosis en pacientes con una clínica vulnerable como los diabéticos, con un sistema inmune deficiente, enfermedades oncológicas y hematológicas, especialmente los pacientes con insuficiencia respiratoria por la enfermedad del COVID - 19 y que a su vez se le asocian las antes mencionadas, facilitando las invasiones por estos agentes oportunistas sin dejar de mencionar las infecciones bacterianas según estudios realizados de aislamientos ambientales ${ }^{(1-3)}$. Se identificó a Rhizopus sp. en las áreas críticas y hospitalización de COVID-19 del Hospital Nacional Almanzor Aguinaga Asenjo; exponiendo placas de Petri con agar Sabouraud durante una hora dentro de las habitaciones, las cuales pasaron un proceso de incubación y aislamiento de colonias; se utilizó lactofenol para la tinción en láminas y se realizó la observación microscópica ${ }^{(4,5)}$. Con la actual alerta epidemiológica declarada por la Organización Panamericana de la Salud (OPS) $)^{(6)}$, que menciona preparar a los servicios de salud para minimizar la morbilidad y mortalidad por mucormicosis asociada a la COVID-19 (CAM) y que el Ministerio de Salud en el Perú (MINSA) ha replicado esta alerta el día 03 de setiembre del presente año(2, $7 \cdot 9)$, esta identificación sirve para tomar medidas de prevención en el Hospital, como la implementación de controles de calidad del aire con límites permisibles para microorganismos de interés clínico, la adecuada limpieza de los ambientes que muchas veces su falta genera contaminaciones cruzadas y la capacitación del trabajador que presta este servicio, además de insistir en el continuo lavado de manos del personal de salud ${ }^{(10-12)}$.

Palabras Clave: Mucormicosis, Rhizopus sp, lactofenol, COVID-19 (Fuente: DeCSBIREME).

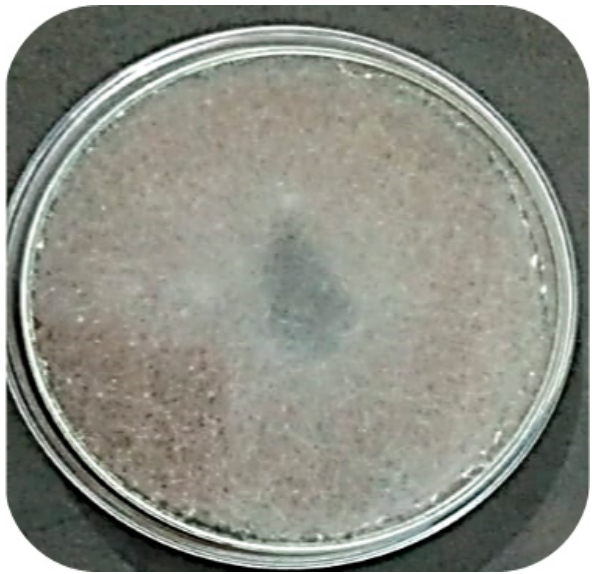

Fotografía 1

Aislamiento de Rhizopus sp en agar Sabouraud con $3-5$ días de crecimiento.

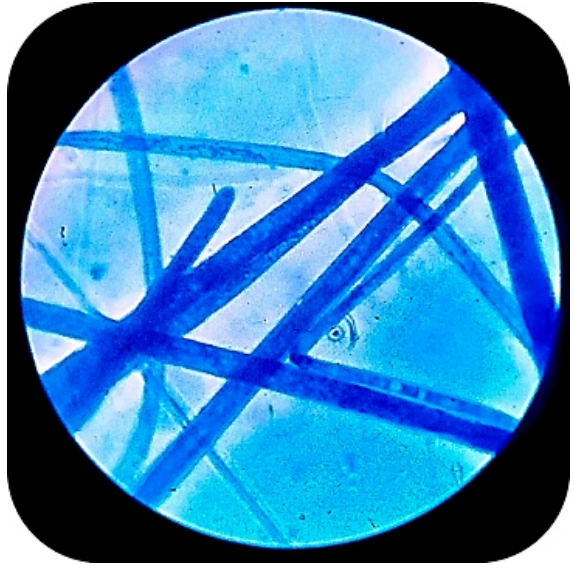

Fotografía 2.

Aumento 400x. Se observa hifas no septadas que corresponde al orden mucorales. Con 3-4 días de crecimiento.
FILIACIÓN

1. Oficina de Inteligencia Sanitaria, Hospital Nacional Almanzor Aguinaga Asenjo, EsSalud, Chiclayo, Perú.

a. Licenciada en Biología.

ORCID

1. Stell Rutvi Paico-Marín 0000-0002-7249-6960

\section{CORRESPONDENCIA}

Stell Rutvi Paico Marín

EMAIL

stellpaicomarin@gmail.com

\section{CONFLICTOS DE INTERÉS}

El autor, niega conflictos de interés.

\section{FINANCIAMIENTO}

Autofinanciamiento.

\section{REVISIÓN DE PARES}

Recibido: $18 / 08 / 2021$

Aceptado: 30/08/2021

\section{COMO CITAR}

Paico-Marín, S. Hongo del orden mucorales identificado en los ambientes del área Covid - 19 de un hospital de alta complejidad. Revista Del Cuerpo Médico Hospital Nacional Almanzor Aguinaga Asenjo, 2021, 14 ( S u p 1), $79-80$. https://doi.org/10.35434/rcmhnaaa. 2021.14Sup1.1178

\section{(c) (i)}

Esta obra está bajo una Licencia Creative Commons Atribución 4.0 Internacional. Versión Impresa: ISSN: 2225-5109 Versión Electrónica: ISSN: 2227-4731 Cross Ref. DOI: 10.35434/rcmhnaaa OJS: https://cmhnaaa.org.pe/ojs 


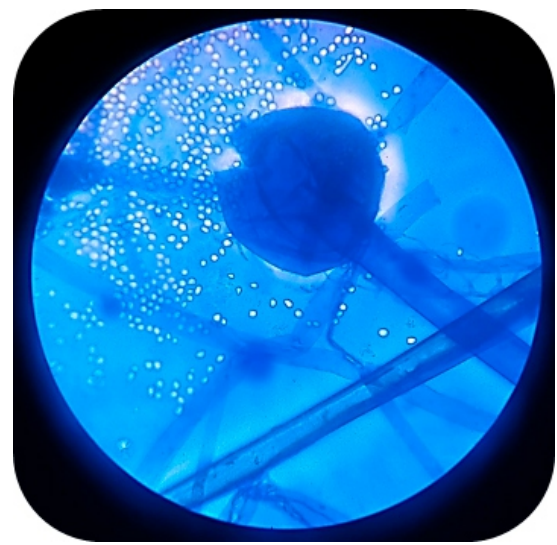

Fotografía 3.

Tinción directa con Lactofenol (azul de algodón) de Rhizopus sp. Aumento $400 x$. Se observa esporangióforo de forma tubular y esporangio en forma de saco expulsando esporas características del orden mucorales con 6 - 8 días de crecimiento.

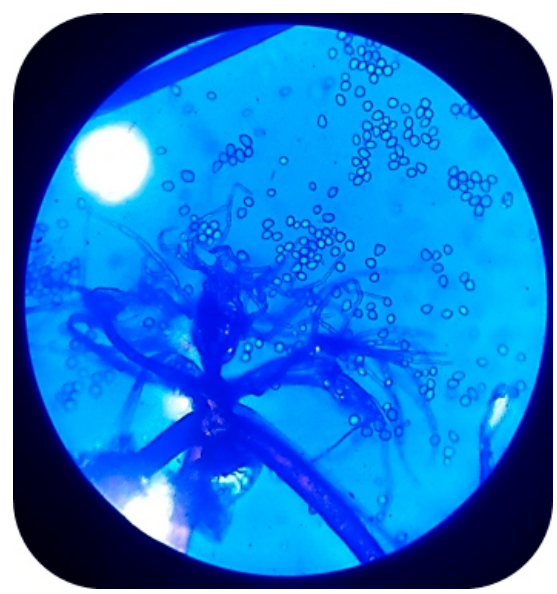

Fotografía 4.

Aumento $400 x$. Se observa estructuras Rizoides muy característico de género Rhizopus del orden mucorales con 6-8 días de crecimiento.

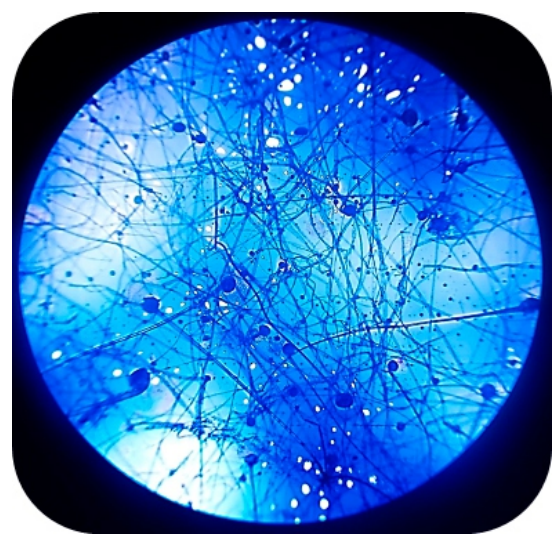

Fotografía 5.

Rhizopus sp. Aumento 100x. Colonia en crecimiento con 7 - 10 días de cultivo.

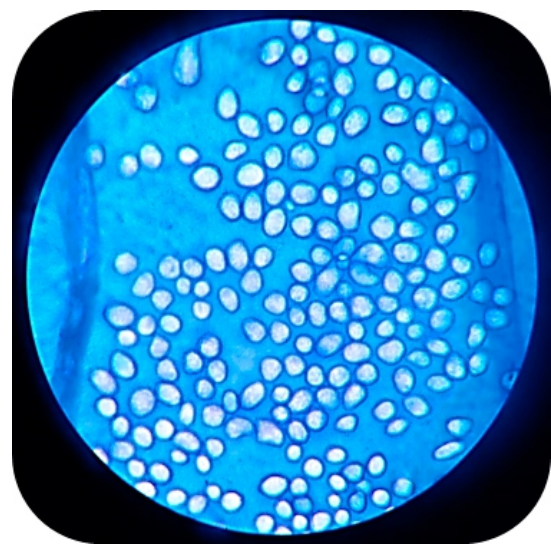

Fotografía 6.

Aumento 1000x. Esporas de forma ovada del género Rhizopus sp. Teñidas con Lactofenol con 7-10 días de crecimiento.

\section{REFERENCIAS BIBLIOGRÁFICAS}

1. Álvarez E. El Subphylum Mucoromycotina: generalidades y aspectos taxonómicos recientes. Boletín Micológico. 2013 junio;(28).

2. Elguera Falcón F, Cumpa Quiróz R. Mucormicosis en pacientes diabéticos post infección por COVID - 19. Rev. Soc. Perú Med Interna. 2020 noviembre; IV(33): p. 176 - 182.

3. Plasencia Dueñas NR, Zegarra RodríguezA, Failoc Rojas VE, Díaz Vélez C. Aislamiento microbiológico de superficies inanimadas en contacto con pacientes en un hospital peruano. Infectio. 2022; 26(1): p. 67-72.

4. Patiño Álvarez B, Vásquez Estévez C. Técnicas Básicas de microbiología observación de hongos filamentosos. Tesis de titulo profesional. Madrid: Universidad Complutense Madrid, Microbiología; 2009 mayo. Report No.: ISSN.

5. Ccuno Carita Y. Hongos oportunistas que contaminan el quirófano, sala de partos y neoonatología del hospital Carlos Monge Medrano de Juliaca-2015. Tesis título profesional. Juliaca: Universidad Nacional del Altiplano - Puno, Biología; 2017.

6. Organization PAH. Alerta Epidemiológica Mucormicosis asociada a la COVID-19. OPS. 2021 junio $11 ;:$ p. 1-6.

7. Dilek A, Ozaras R, Oskaya S, Sunbul M, Itir Sen E. COVID-19-associated mucormycosis: Case report and systematic review. Travel Medicine and Infectious Disease. 2021 agosto 26; 44: p. 2-9.

8. Rodrigues Morales J, Mamani García CS, Nuñez Lupaca JN, León Figueroa DA, Olarte Durand M, Yrene Cubas RA, et al. COVID-19 y mucormicosis en América Latina: una preocupación emergente. Medicina de viajes y enfermedades infecciosas. 2021 noviembre diciembre; 44.

9. Salud Md. MINSA CDC. [Online].; 2021 [cited 2021 setiembre 06. A v a i l a b l e f r o m https://www.dge.gob.pe/portalnuevo/centros/alerta-yrespuesta/alerta-y-respuesta/.

10. Preventiva SAdM. Recomendaciones para la monitorización de la calidad microbiológica del aire (Bioseguridad ambiental) en zonas hospitalarias de riesgo. Andalucía: Sociedad Andaluza de Medicina Preventiva y Salud Pública; 2016.

11. Tantalean Garrido LE, Díaz Vélez C. Conocimiento sobre limpieza hospitalaria en los trabajadores de limpieza en los hospitales de Essalud de la Lambayeque el 2019. Revista experiencia en medicina del hospital Regional Lambayeque. 2021 julio 14; 7(2): p. 63-69.

12. Ezpeleta Baquedano C, Barrios Andrés JL, Delgado Ibarren García Campero A. Control microbiológico ambiental. Enfermedades infecciosas y microbiología clínica. 2013 abril; 31(3). 